\title{
Apoptosis Induced by (+)-Betulin Through NF-kB Inhibition in MDA-MB-231 Breast Cancer Cells
}

\author{
GERARDO D. ANAYA-EUGENIO ${ }^{1}$, NICOLE A. EGGERS ${ }^{1}$, YULIN REN ${ }^{1}$, JOSÉ RIVERA-CHÁVEZ ${ }^{2}$, \\ A. DOUGLAS KINGHORN ${ }^{1}$ and ESPERANZA J. CARCACHE DE BLANCO ${ }^{* *}$ \\ ${ }^{1}$ Division of Medicinal Chemistry and Pharmacognosy, College of Pharmacy, \\ The Ohio State University, Columbus, OH, U.S.A.; \\ ${ }^{2}$ Departamento de Productos Naturales, Instituto de Química, \\ Universidad Nacional Autónoma de México, Ciudad Universitaria, Mexico
}

\begin{abstract}
Background/Aim: This study aimed to uncover the effects of (+)-betulin on the $N F-k B$-apoptotic pathway in $M D A-M B-231$ cells, and determine its toxicity and protein expression in vivo. Materials and Methods: Cell cytotoxicity and toxicity were determined using the SRB assay and a zebrafish model, respectively. Western blot, mitochondrial transmembrane potential (MTP), and computational modeling analysis were performed. Results: (+)-betulin inhibited the growth of MDA-MB-231 cells, but did not induce toxicity in zebrafish. (+)-Betulin inhibited the activity of $N F-k B$ p65 in silico and in vitro. In cells, (+)-betulin down-regulated $N F-k B$ p50 and 65, IKK $\alpha$ and $\beta, I C A M-1$ and bcl-2 expressions. Cell co-treatment with (+)-betulin and TNF $\alpha$ increased the (+)betulin cytotoxic potential. Moreover, (+)-betulin induced the loss of MTP. Furthermore, (+)-betulin, in zebrafish, downregulated the expression of $N F-k B p 65, I K K \alpha, I K K \beta$ and procaspase-3. Conclusion: The results contribute to the understanding of the mode of action on apoptosis induction by inhibiting $N F-k B$ pathway in MDA-MB-231 cells.
\end{abstract}

Cancer is one of the major public health problems worldwide. In women, breast cancer is a leading cause of death and the most frequent type of cancer (1). The major breast cancer sub-types are based on immunohistochemical properties, such as hormone receptor-positive/ERBB2-negative, ERBB2-positive, and triplenegative breast cancer (TNBC). TNBC does not express any of the progesterone and estrogen receptors or human epidermal

This article is freely accessible online.

Correspondence to: Dr. Esperanza J. Carcache de Blanco, Division of Medicinal Chemistry and Pharmacognosy, College of Pharmacy, The Ohio State University, Columbus, OH, U.S.A. E-mail: carcache-de-blan.1@osu.edu

Key Words: (+)-betulin, NF-kB, MDA-MB-231, zebrafish, apoptosis. growth factor receptor 2, and it is considered the most aggressive (2). In TNBC, chemotherapy and radiotherapy are commonly used, after lumpectomy. However, this kind of breast cancer frequently becomes resistant until it develops a metastatic disease, turning it into the main cause of death in breast cancer (3). Thus, investigating molecules for TNBC seems an attractive approach to discover new potential chemotherapies.

(+)-Betulin (3-lup-20(29)-ene-3 $\beta, 28$-diol) is a pentacyclic triterpenoid previously isolated from many plant species, especially from the Betulaceae family (4-6). A broad range of biological activities has been reported for (+)-betulin, including antibacterial, antifungal, antiviral, anti-inflammatory, antidiabetic, anti-gastritis and antiparasitic activities. Nonetheless, the cytotoxic and antiproliferative activity of (+)betulin has been the most studied, including with human cancer cell lines of the lung, breast, prostate, stomach, ovarian, leukemia, cervical, hepatic, pancreatic and central nervous system types, and others (4-7). In animal cancer cells, (+)betulin has shown inhibition of cancer cell growth in canine T-cell (CL-1), B-cell (CLBL-1) lymphoma, and canine osteosarcoma (D-17) cell lines (8). Among human breast cancer cells, (+)-betulin has been demonstrated to induce cytotoxicity in MCF-7 (9), T47D (10), HBL-100 and MDAMB-231 cells (11). Recent studies have shown that (+)-betulin induces apoptosis by regulating protein activation of the mitochondrial-intrinsic pathway (9). However, despite the known cytotoxic activity of (+)-betulin, its mechanism of action in breast cancer cells is not well understood. Thus, the main aims of this study were to study the involvement of (+)betulin on NF-kB induced apoptosis in MDA-MB-231 cells and determine its in vivo effects in zebrafish.

\section{Materials and Methods}

Chemicals and reagents. (+)-Betulin ( $>95 \%$ purity) was synthesized by reduction of the $\mathrm{C}-28$ carboxylic acid group from (+)-betulinic acid, isolated from Cyrilla racemiflora $(12,13)$, and purchased from SigmaAldrich ( $>98 \%$ purity; St Louis, MO, USA), together with staurosporine, 
Table I. Target-based assay activity of (+)-betulin in MDA-MB-231 breast cancer cells.

\begin{tabular}{lccc}
\hline Compound & SRB $^{\mathrm{a}}$ & NF-kB $^{\mathrm{b}}$ & MTP $^{\mathrm{c}}$ \\
\hline $\begin{array}{l}\text { (+)-Betulin } \\
\text { Paclitaxel }^{\mathrm{d}}\end{array}$ & 9.5 & 3.9 & 6.5 \\
Rocaglamide $^{\mathrm{d}}$ & 0.3 & 0.2 & \\
Staurosporine $^{\mathrm{d}}$ & & & 0.5 \\
\hline
\end{tabular}

${ }^{\mathrm{a}} \mathrm{IC}_{50}$ value $(\mu \mathrm{M})$ in MDA-MB-231 breast cancer cells. SRB assay: Sulforhodamine B assay. ${ }^{\mathrm{I}} \mathrm{IC}_{50}$ value $(\mu \mathrm{M})$ for inhibition of nuclear factor kappa B (NF-kB p65). ${ }^{\mathrm{c} E C_{50}}$ value $(\mu \mathrm{M})$ for loss of mitochondrial transmembrane potential (MTP). ${ }^{\mathrm{d}}$ Positive controls.

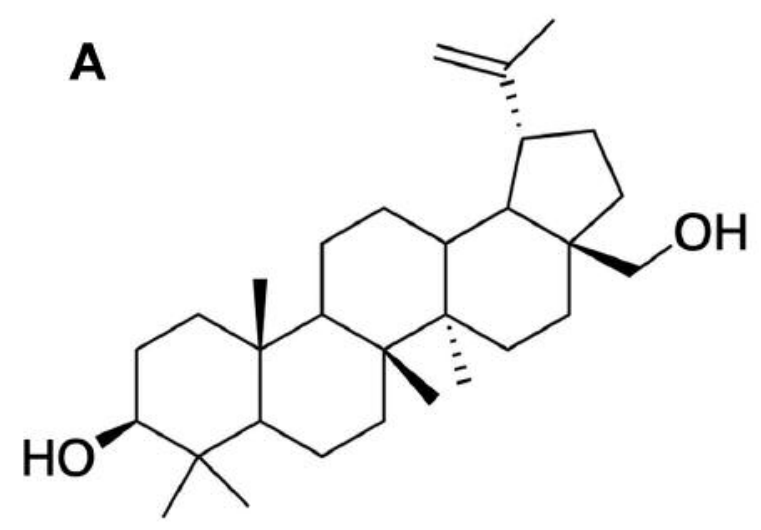

Figure 1. Continued cycloheximide, paclitaxel, and sulforhodamine B. Rocaglamide was purchased from Enzo Life Sciences, Inc (Farmingdale, NY, USA). Tumor necrosis factor- $\alpha(\mathrm{TNF} \alpha)$ and NE-PER ${ }^{\circledR}$ nuclear and cytoplasmic extraction reagents kits were obtained from Thermo Scientific (Rockford, IL, USA). The mitochondrial transmembrane potential (MTP) assay kit was purchased from Cayman Chemical Company (Ann Arbor, MI, USA). An ELISA ${ }^{\mathrm{TM}}$ NF-kB p65 kit was obtained from Invitrogen (Carlsbad, CA, USA). Primary antibodies (anti-NF-kBp65, anti-NF-KBp50, anti-IKK $\alpha$, anti-IKK $\beta$, anti-caspase-3, anti-caspase-7, anti-Bcl-2, anti-ICAM- 1 and anti- $\beta$-actin) were purchased from Cell Signaling Technologies (Beverly, MA, USA). Anti-rabbit or anti-mouse horseradish peroxidase (HRP)-conjugated antibody was purchased from Santa Cruz Biotechnology, Inc (Santa Cruz, CA, USA).

Sample preparation. (+)-Betulin and the controls (paclitaxel, rocaglamide and staurosporine) were dissolved in $100 \%$ DMSO to prepare stock solutions of 10 or $4 \mathrm{mg} / \mathrm{ml}$. Final DMSO concentration for MDA-MB-231 cells were $0.2 \%$ and $0.03 \%$ for Western blot and zebrafish assays.

Cell culture. MDA-MB-231 breast cancer cells were obtained from American Type Culture Collection, Manassas, VA, USA. Monolayer cells were cultured using T75 tissue culture flasks in Roswell Park Memorial Institute medium (RPMI), containing 10\% fetal bovine serum and $1 \%$ antibiotic-antimycotic from Gibco. Cells were kept at $37^{\circ} \mathrm{C}$ and in an atmosphere with $5 \%$ of $\mathrm{CO}_{2}$.

Antiproliferative assays. Antiproliferative activity of (+)-betulin was evaluated in triplicate on MDA-MB-231 cells, using a sulforhodamine B (SRB) assay as reported previously (14), in three independent experiments. The time of treatment for co-treatment with (+)-betulin $(5 \mu \mathrm{M})$ and $\mathrm{TNF} \alpha(50 \mathrm{ng} / \mathrm{ml})$ in MDA-MB-231 cells were 48 or $72 \mathrm{~h}$.

$N F-k B$ inhibition assay. This assay was performed according to a previously described procedure (14). Briefly, MDA-MB-231 breast cancer cells were treated with (+)-betulin $(0-50 \mu \mathrm{M})$ for $5 \mathrm{~h}$. The chemiluminescent signal was measured in the plate reader (Fluostar Optima, BMG Labtechnologies Gmbh, Inc. Durham, NC, USA). Rocaglamide was used as a positive control.

Docking of (+)-betulin. Molecular docking between (+)-betulin and the NF-kB isoforms p50, p52 and p65 used crystallographic structures from the Protein Data Bank site (PDB:1NFK, 1A3Q and 1MY5, respectively). All hydrogens (polar and no polar) and Kollman charges were assigned using an AutoDock Tools package 1.5.4 (1516). The ligand starting conformation was in energy-minimized form with geometric optimization using the program Spartan 10 with a semi-empirical force field. (+)-Betulin was evaluated by assigning the Gasteiger-Marsilli atomic charges and non-polar hydrogens using AutoDockTools 1.5.4 (http://mgltools.scripps.edu/). Blind docking carried out with AutoDock4 software (http://autodock.scripps.edu/) used default parameters, except for the number of GA runs (100) and the Lamarkian genetic algorithm with a local search and 25 million energy evaluations (Long. Evals.) per run. Protein was held rigid during the docking process while ligands were allowed to be flexible. The grid box size was $126 \AA \times 126 \AA \times 126 \AA$ in the $\mathrm{x}, \mathrm{y}$ and $\mathrm{z}$ dimensions, with the center of the grid corresponding to the protein. The predicted docked complexes (protein-ligand) were those conformations showing the lowest binding energy. Estimated inhibition constant (ki) were calculated from the docking energy displayed by AutoDock following the equation $k i=\exp (\Delta \mathrm{G} \times$ $1000 / \mathrm{RT}$ ), where $\Delta \mathrm{G}$ is the docking energy, $\mathrm{R}$ is the universal constant of an ideal gas $\left(1.98719 \mathrm{cal} \mathrm{K}^{-1} \mathrm{~mol}^{-1}\right)$, and $\mathrm{T}$ is the temperature $(298.15 \mathrm{~K})$.

Mitochondrial transmembrane potential (MTP) assay. The JC-1 dye (5,5',6,6'-tetrachloro-1,1',3,3'-tetraethyl-benzimidazoylcarbocyanine iodide) was used to determine the effect of $(+)$-betulin $(0-50 \mu \mathrm{M})$ on the MTP in MDA-MB-231 cells after $5 \mathrm{~h}$ of treatment. Staurosporine $(8 \mu \mathrm{M})$ was used as positive control. This procedure was performed according to the JC-1 Mitochondrial Membrane Potential Assay Kit from Cayman Chemical. The results are presented in $\mu \mathrm{M}$ as the halfmaximal effective concentration $\left(\mathrm{EC}_{50}\right)$ to induce loss of MTP in relation to the control.

Western blot analysis. The effects of (+)-betulin $(0-50 \mu \mathrm{M})$ on apoptotic-proteins and NF-kB pathway proteins were evaluated by immunoblots, as described previously (14).

Toxicity in vivo. A zebrafish (Danio rerio) model (embryos $24 \mathrm{~h}$ post-fertilization, hpf) was used to evaluate the developmental toxicity of (+)-betulin. This assay was performed following a previously reported procedure (14). Embryos were provided by the Department of Neuroscience, The Ohio State University (OSU). All protocols and procedures were approved by The Ohio State 

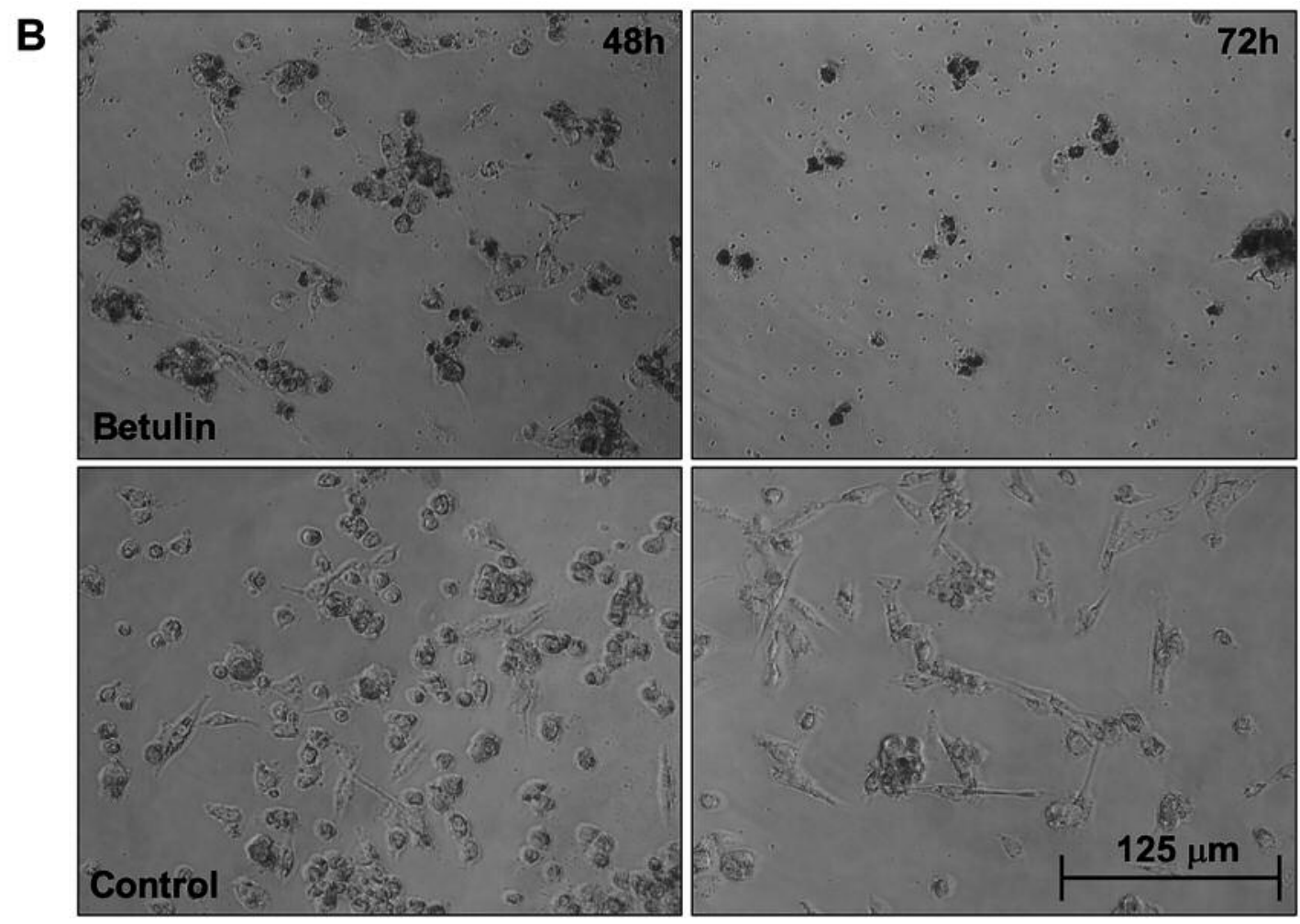

C
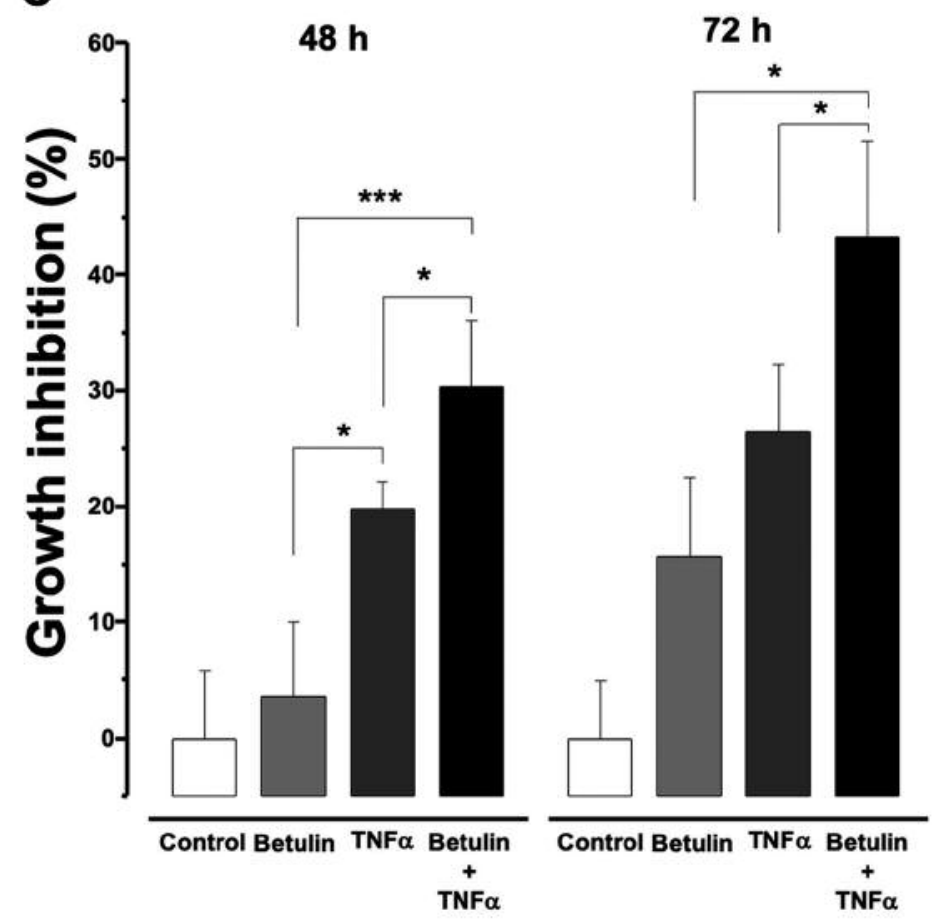

Figure 1. Cytotoxicity of (+)-betulin in MDA-MB-231 breast cancer cells. (A) Structure of (+)-betulin; (B) representative microscopic (20x) morphology view of MDA-MB-231 cells after 48 and $72 \mathrm{~h}$ of treatment with (+)-betulin $(15 \mu M)$ or control (DMSO $0.2 \%)$. (C) Cytotoxic effects of co-treatment of (+)-betulin and TNFa in MDA-MB-231 cells, using a SRB assay. Cells were treated for 48 and 72 h either with (+)-betulin (5 $\mu M)$ or TNFa $(50 \mathrm{ng} / \mathrm{ml})$ or both. Data are expressed as the means $\pm S E M(n=9)$ and analyzed by one-way ANOVA, using Dunnett's multiple-comparison test $(* p<0.05, * * * p<0.01)$. 
University's Institutional Animal Care and Use Committee (OSU IACUC protocol number 2014A00000006, entitled "Vertebrate Model for Natural Product Drug Discovery”; PI: Esperanza J. Carcache de Blanco).

Statistical analysis. All data are presented as the means \pm standard error of the mean (SEM). All measurements and analyses were carried out in triplicate on two or three independent experiments. TableCurve 2D 4v (System Software Inc.) and Origin 8.0 (OriginLab. Inc.) was used for statistical evaluations to obtain $\mathrm{IC}_{50}$ or $\mathrm{EC}_{50}$ values. To obtain significant values, an analysis of variance (ANOVA) or an unpaired Student's $t$-test were performed, followed by a post-hoc Dunett's test using GrapPad Prism 5.0 software. Values of $* p<0.05, * * p<0.01, * * * p<0.001$ indicated significant differences between the groups compared with the controls.

\section{Results}

Cytotoxicity of (+)-betulin on MDA-MB-231 breast cancer cells, using a SRB assay. After $72 \mathrm{~h}$ of treatment with (+)betulin (Figure 1), the number of cells was significantly decreased when compared to the control, with an $\mathrm{IC}_{50}$ of 9.5 $\mu \mathrm{M}$ (Table I). Also, (+)-betulin induced a reduction in cell size and changes in cell membrane morphology, similar to shrinkage of the cytoplasm (Figure 1B).

Effects of (+)-betulin on $N F-k B$ in MDA-MB-231 cells. After $5 \mathrm{~h}$ of treatment in a chemiluminescence assay, (+)-betulin showed NF-kB inhibition with an $\mathrm{IC}_{50}$ value of $3.9 \mu \mathrm{M}$ (Table I), suggesting that (+)-betulin binds to or interacts with the NF-kB complex.

Structural insights on the putative binding mode of (+)-betulin with the NF-kB complex were gathered by molecular docking, using the crystallographic structures of NF-kB p50 (1NFK), NF$\mathrm{kB}$ p52 (IA3Q), and NF-kB p65 (1MY5). The binding sites predicted by AutoDock for NF-kB p50, p52 and p65 are depicted in Figure 2 (A-C, respectively). In all cases, the main interactions that govern the coupling were hydrophobic, although hydrogen bonds ranging from 1.9-2.9 $\AA$ were also observed with polar or charged amino acids (Figure 2).

The effects of (+)-betulin on the NF-kB complex such as protein expression of the NF-kB p50 and p65 subunits on MDA-MB-231 cells was determined using western blot. Figure $3 \mathrm{~A}$ and $\mathrm{B}$ suggest that after $5 \mathrm{~h}$ of treatment of MDAMB-231 cells, (+)-betulin induced in a concentrationdependent manner down-regulation of both NF-kB p50 and p65 $(p \leq 0.05)$. In this way, the inhibitory activity and the reduction in the expression of NF-kB subunits in MDA-MB231 cells were correlated and confirmed.

To explore if (+)-betulin modulates other proteins in the NF$\mathrm{KB}$ pathway, western blot analysis of the expression of IKK $\alpha$, IKK $\beta$ and ICAM- 1 was performed. Figure $3 \mathrm{C}$ shows that (+)betulin reduced only IKK $\alpha$ expression at $50 \mu \mathrm{M}(p<0.05)$; however, from 0.5 to $50 \mu \mathrm{M}$, (+)-betulin reduced the levels of IKK $\beta$ (Figure 3D, $p \leq 0.01$ ). (+)-Betulin also down-regulated
ICAM-1 expression at 5 and $50 \mu \mathrm{M}$ (Figure 3E, $p<0.01$ and $p<0.05)$, respectively. All these results support the regulation of NF-kB complex by (+)-betulin and the reduction in number of MDA-MB-231 cells after treatment with (+)-betulin can be related with down-regulation of ICAM-1.

Co-treatment effects in MDA-MB-231 cells by (+)-betulin and $T N F \alpha$. Figure $1 \mathrm{C}$ shows cytotoxic activity of (+)betulin $(5 \mu \mathrm{M}), \mathrm{TNF} \alpha(50 \mathrm{ng} / \mathrm{ml})$ and co-treatment with (+)betulin and $\mathrm{TNF} \alpha(5 \mu \mathrm{M}$ and $50 \mathrm{ng} / \mathrm{ml})$, respectively. At both 48 and $72 \mathrm{~h}$, the cytotoxicity of (+)-betulin was remarkably increased by co-treatment with TNF $\alpha(p \leq 0.05)$. These results suggest a possible synergistic effect between (+)-betulin and TNF $\alpha$.

Effects of (+)-betulin on mitochondrial transmembrane potential (MTP) in MDA-MB-231 cells. A lipophilic staining cation JC-1 assay was performed. The results showed that (+)-betulin significantly induced loss of MTP in MDA-MB231 cells at $50 \mu \mathrm{M}(p<0.001)$, after $5 \mathrm{~h}$ of treatment, in a similar fashion to the positive control staurosporine $(8 \mu \mathrm{M}$ $p<0.05$, Figure $4 \mathrm{~A})$. The effective concentration estimated to trigger $50 \%$ of loss of MTP $\left(\mathrm{EC}_{50}\right)$ was calculated as $6.5 \mu \mathrm{M}$ (Table I). These results suggest that inhibition of NF-kB by (+)-betulin is associated with stimulation of the intrinsic apoptotic pathway.

Effects of (+)-betulin on the expression of Bcl-2 in MDA-MB231 cells. Western blot was used to determine the effect of (+)betulin on expression of the antiapoptotic Bcl-2 protein. After $5 \mathrm{~h}$ of MDA-MB-231 cells treatment with (+)-betulin, the concentrations at 5 and $50 \mu \mathrm{M}$ induced a significant downregulation ( $p<0.05$ and $p<0.001$, respectively) of the $\mathrm{Bcl}-2$ protein in the same way as the positive control, rocaglamide ( 3 $\mu \mathrm{M}, p<0.01$, Figure 4B). These results suggest that inhibition of NF-kB by (+)-betulin in MDA-MB-231 cells could correlate to induction of mitochondrial apoptosis.

Toxicity in vivo effects of (+)-betulin in zebrafish. To obtain preliminary data in vivo, an initial toxicity assay was executed in zebrafish (Danio rerio). Embryos at $24 \mathrm{~h}$ post fertilization (hpf) were treated with a single dose $(50 \mu \mathrm{M})$ of (+)-betulin or cycloheximide or DMSO $(0.001 \%)$. After $24 \mathrm{~h}$ of treatment, (+)-betulin delayed hatching of the eggs compared to the vehicle, with no visible effects on development as shown for cycloheximide (positive control) (Figure 5A). However, at 48 $\mathrm{h}$ after treatment, all eggs treated with (+)-betulin hatched in the same manner as the vehicle without any visible body abnormalities, while for cycloheximide, a continued delay in development was observed (Figure 5A). These findings suggest that (+)-betulin exhibited non-observable toxicity in zebrafish at a high concentration $(50 \mu \mathrm{M})$ when compared with cycloheximide, which encouraged further studies. 

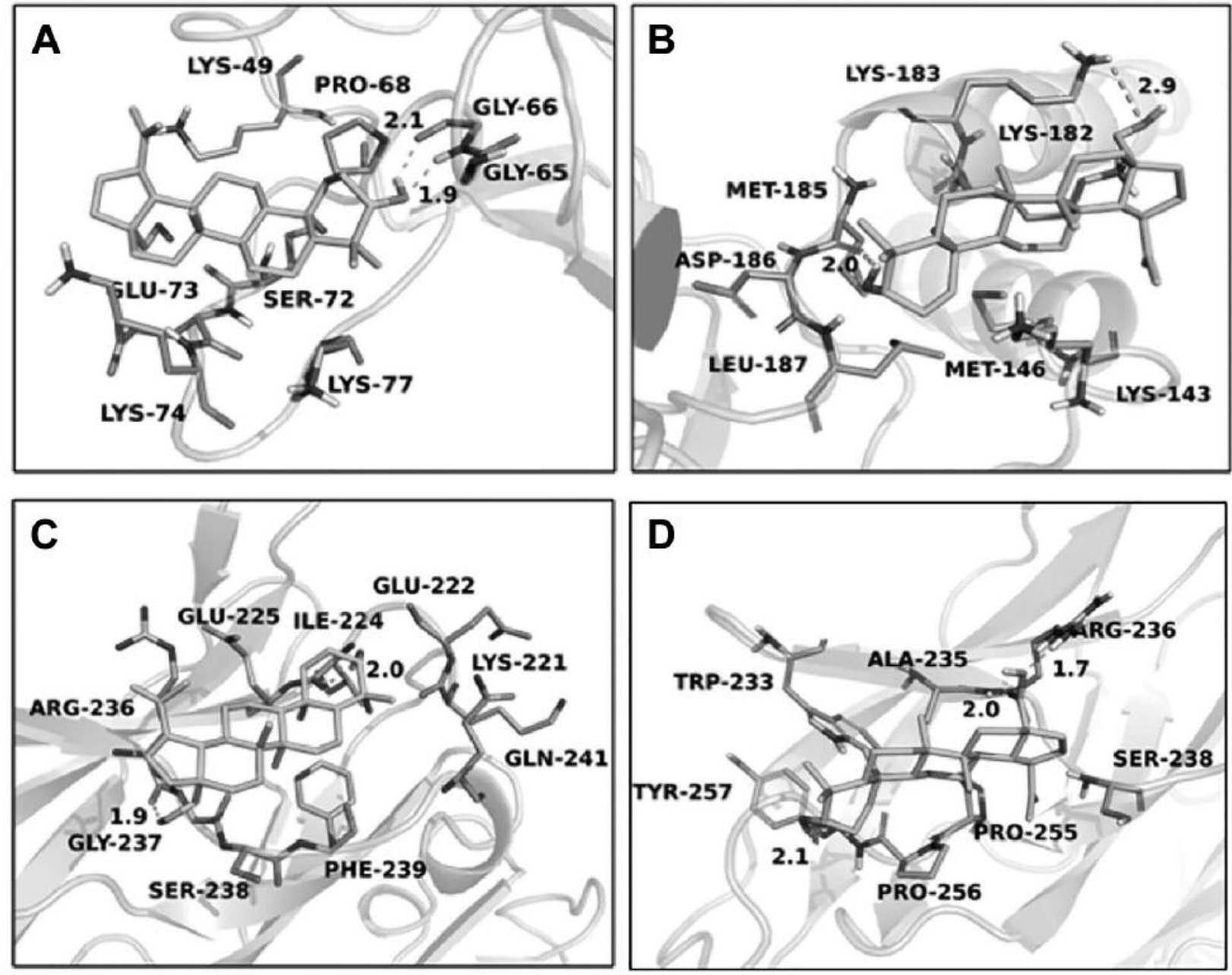

\begin{tabular}{cccc}
\hline NF-kB complex & $\begin{array}{c}\text { Estimated } \\
\text { free energy } \\
\text { of binding } \\
\text { (kcal/mol) }\end{array}$ & $\begin{array}{c}\text { Estimated } \\
\text { inhibition } \\
\text { constant, } \boldsymbol{k}_{\boldsymbol{i}}(\boldsymbol{\mu} \mathrm{M})\end{array}$ & Amino acids \\
\hline p50(1NFK) & -5.63 & 74.52 & $\begin{array}{c}\text { Lys-49, Gly-65, Gly-66, Pro-68, } \\
\text { Ser-72, Glu-73, Lys-74 and Lys- } \\
77\end{array}$ \\
\hline p52 (1A3Q) & -5.99 & 40.39 & $\begin{array}{c}\text { Lys-143, Met-146, Lys-182, Lys- } \\
\text { 183, Met-185, Asp-186 and } \\
\text { Leu-187 }\end{array}$ \\
\hline p65(1MY5) & -8.49 & 0.596 & $\begin{array}{c}\text { Lys-221, Glu-222, lle-224, Glu- } \\
225, \text { Arg-236, Gly-237, Ser-238, } \\
\text { Phe-239 and GIn-241 }\end{array}$ \\
\hline
\end{tabular}

Figure 2. Molecular docking with NF-kB complex. Docking of (+)-betulin with PDB structures: (A) NF- $k B$ p50 (INFK); (B) NF-kB p52 (IA3Q); (C) NF-kB p65 (1MY5); and (D) docking of betulinic acid with NF-kB p65 (1MY5). Gray Dotted lines show distance and potential hydrogen bonding between $N F-K B$ (light gray) complex and (+)-betulin (dark gray) ang. 
A

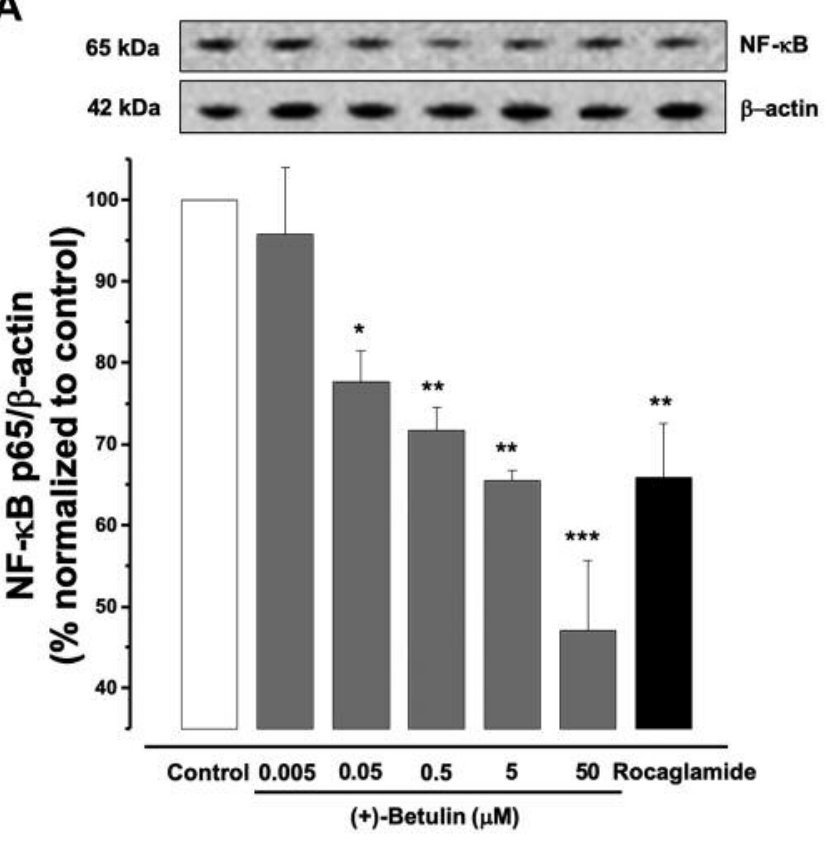

C
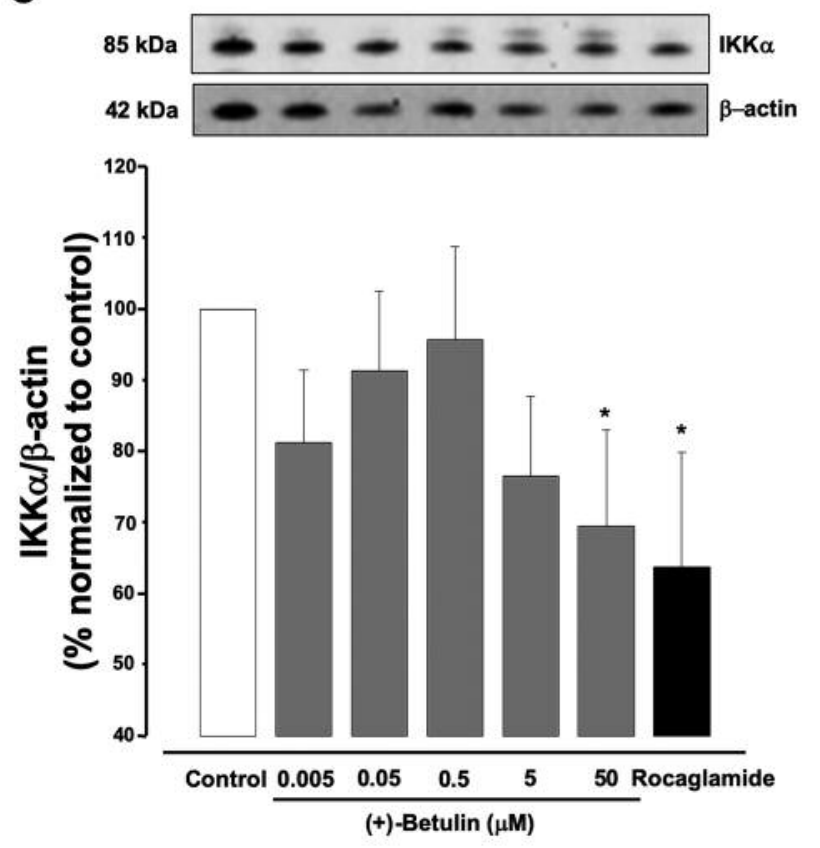

Effects on zebrafish $N F-\kappa B$ pathway protein expression. The effect of (+)-betulin on the expression of NF-KB pathway related-proteins was evaluated, using zebrafish at $72 \mathrm{~h}$. The results in Figure 5B show that treatment with (+)-betulin reduced the levels of NF-kB p65, IKK $\alpha$, IKK $\beta$, and
B
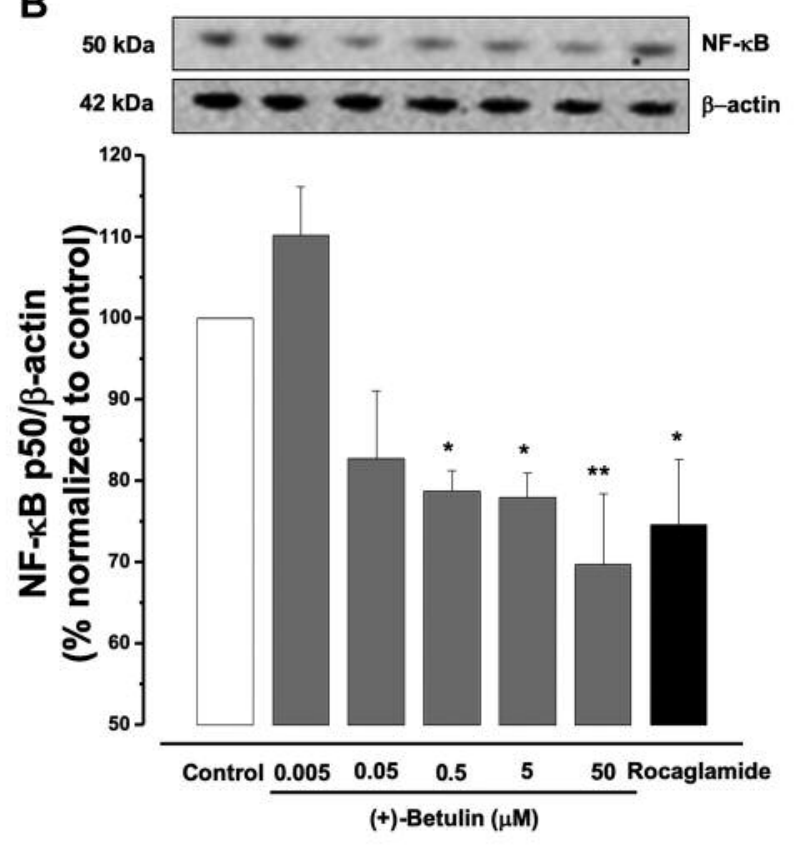

D
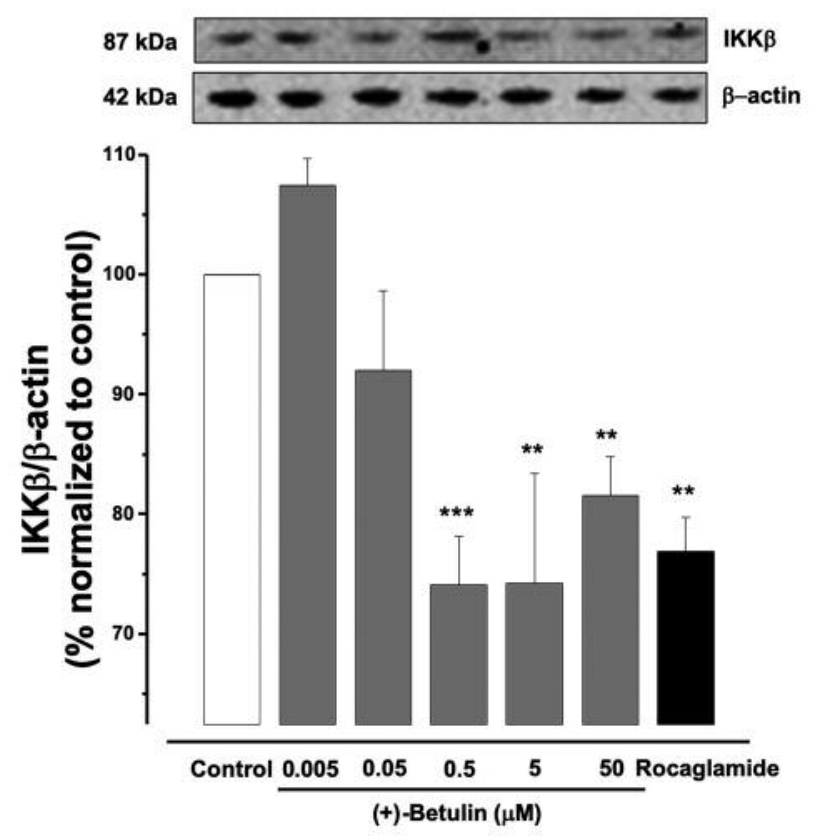

Figure 3. Continued

procaspase-3 protein, but no changes were observed for NF-kB p50 and procaspase-7. These preliminary data demonstrated that (+)-betulin can inhibit the NF-KB complex in vivo, with these results in agreement with those found in vitro with MDA-MB-231 breast cancer cells. 


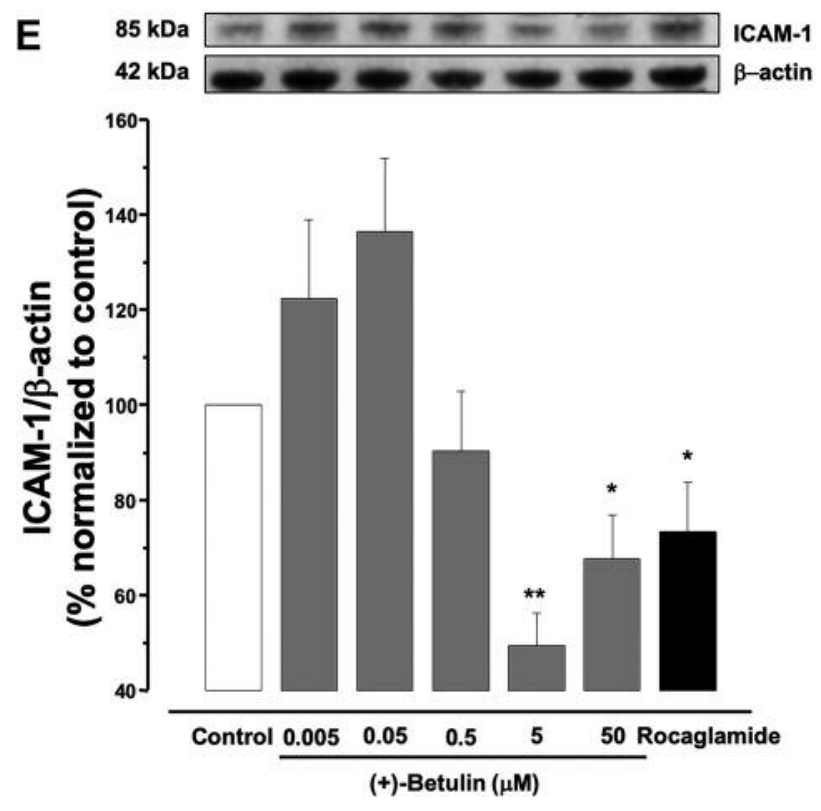

Figure 3. Effects of (+)-betulin on the $N F-k B$ signaling pathway in MDA-MB-231 cells. Cells were treated for $5 \mathrm{~h}$ with (+)-betulin (0-50 $m M)$ or rocaglamide used as the positive control $(3 \mu M)$. Western blotting was performed to evaluate: (A) NF-kB p50 and (B) p65; (C), $I K K \alpha$ and $(D) I K K \beta$; and $(E) I C A M-1$ protein expression. Data are expressed as the means $\pm S E M(n=3)$ and analyzed by one-way ANOVA using Dunnett's multiple-comparison test $\left({ }^{*} p<0.05, * * p<0.01\right.$, $* * * p<0.01)$ of three independent assays.

\section{Discussion}

In this study (+)-betulin exhibited significant cell growth inhibition in human breast cancer cells and in previous studies it did so against canine cancer cells (8). The present study demonstrated that (+)-betulin inhibits the NF-kB complex both in vitro (in MDA-MB-231 breast cancer cells), in vivo (in zebrafish) and in silico. An in silico affinity comparison between the interaction of NF-kB p65 (1MY5) with (+)betulin or its oxidized derivative betulinic acid (BA) resulted in a $\mathrm{Ki}$ value for (+)-betulin of $0.596 \mu \mathrm{M}$ and for BA of 0.851 $\mu \mathrm{M}$ (Figure 2D), suggesting (+)-betulin shows a slightly higher affinity for NF-kB than BA. The results suggested that (+)-betulin binds to NF-kB p50 in a pocket formed by amino acids Lys-49, Gly-65, Gly-66, Pro-68, Ser-72, Glu-73, Lys-74, and Lys-77. The binding pocket with NF-kB p52 included amino acids Lys-143, Met-146, Lys-182, Lys-183, Met-185, Asp-186, and Leu-187, whereas the union site for NF-kB p65 included the residues Lys-221, Glu-222, Ile-224, Glu-225, Arg-236, Gly-237, Ser-238, Phe-239, and Gln-241. NF-kB is a transcriptional factor implicated in several cellular process such as inflammation, immune response, and tumorigenesis (17). In cancer cells, NF-kB has been related to cell proliferation, apoptosis evasion, angiogenesis, and metastasis.
Furthermore, NF-kB is constitutively found active in several cancer cells (18). Thus, inhibition of NF-kB activity leads to tumor regression and induces apoptosis, making the NF-kB pathway a promising therapeutic target (19).

Previous studies indicated that (+)-betulin might induce cell death by triggering intrinsic apoptosis-related genes in HBL-100 and MDA-MB-231 cells (11). Apoptosis is characterized by a series of morphological and biochemical features, and could be effected by intrinsic or extrinsic pathways (20). The first pathway is controlled by the mitochondria and, it is mainly activated by cellular stress or damage signals. The second one is stimulated by extracellular factors, which interact with membrane receptors, especially cell death receptors (CDR) family. Eventually, both pathways can end up in the activation of cysteine proteases family (2123). NF-kB pathway is also activated by stimulation of some CDR (17-19). Thus, the cytotoxic effect of (+)-betulin in MDA-MB-231 cells could be induced by crosstalk of the intrinsic and extrinsic apoptotic pathways.

Members of the NF-kB family have been identified as p50, p52, p65 (RelA), RelB, and c-Rel. Combinations of these proteins form homo- or heterodimers and the most abundant heterodimer in cells is the p65/p50 complex (24). (+)-Betulin showed inhibition of activity and downregulation of $\mathrm{NF}-\mathrm{kB}$ p65 and $\mathrm{p} 50$. These results are in agreement with those found in human cardiac AC16 noncancerous cells, where (+)-betulin blocked the transcriptional activity, reduced the nucleus concentration, and reduced the active form of NF-kB p65 (25). Also, in RAW 264.7 cells, (+)-betulin inhibited the translocation to the nucleus of NFkB p65 (26). However, no previous reports were found on the effects of (+)-betulin on NF-kB elements in MDA-MB231 cells. In a previous study, Jiao et al. (2019) demonstrated that treatment with the betulin oxidized derivative betulinic acid (BA) of MDA-MB-231 cancer cells suppressed the NF-kB p-65/p65 and p-IkB $\alpha$ protein levels (27). Similar results were shown in the nuclear p65, suggesting that BA inhibits aerobic glycolysis in MDA-MB231 cells through the Cav-1/NF-kB/c-Myc pathway. Further studies are needed to verify nuclear p65 down-regulation of (+)-betulin in MDA-MB-231 cells.

NF-kB signaling may be activated by canonical and noncanonical pathways. In the canonical pathway, ubiquitination of IkB by IKK $\alpha, \operatorname{IKK} \beta$ and IKK $\gamma$ is required, and the main $\mathrm{NF}-\mathrm{kB}$ dimers involved are p65/p50 and $\mathrm{c}-\mathrm{Rel} / \mathrm{p} 50$. In the non-canonical pathway, there is no $\mathrm{IkB}$, although activation of NF-kB inducing kinase (NIK) prompts phosphorylation of the homodimer IKK $\alpha / \mathrm{IKK} \alpha$, promoting ubiquitination of $\mathrm{p} 100$ to become p52. Then, RelB/p52 is translocated to the nucleus to express several genes $(17,24)$. Hence, the IKK complex is very important in NF- $\mathrm{KB}$ signaling. (+)-Betulin reduced in MDA-MB-231 cells the expression of IKK $\alpha$ and $\beta$ proteins. However, down-regulation of IKK $\beta$ was induced 

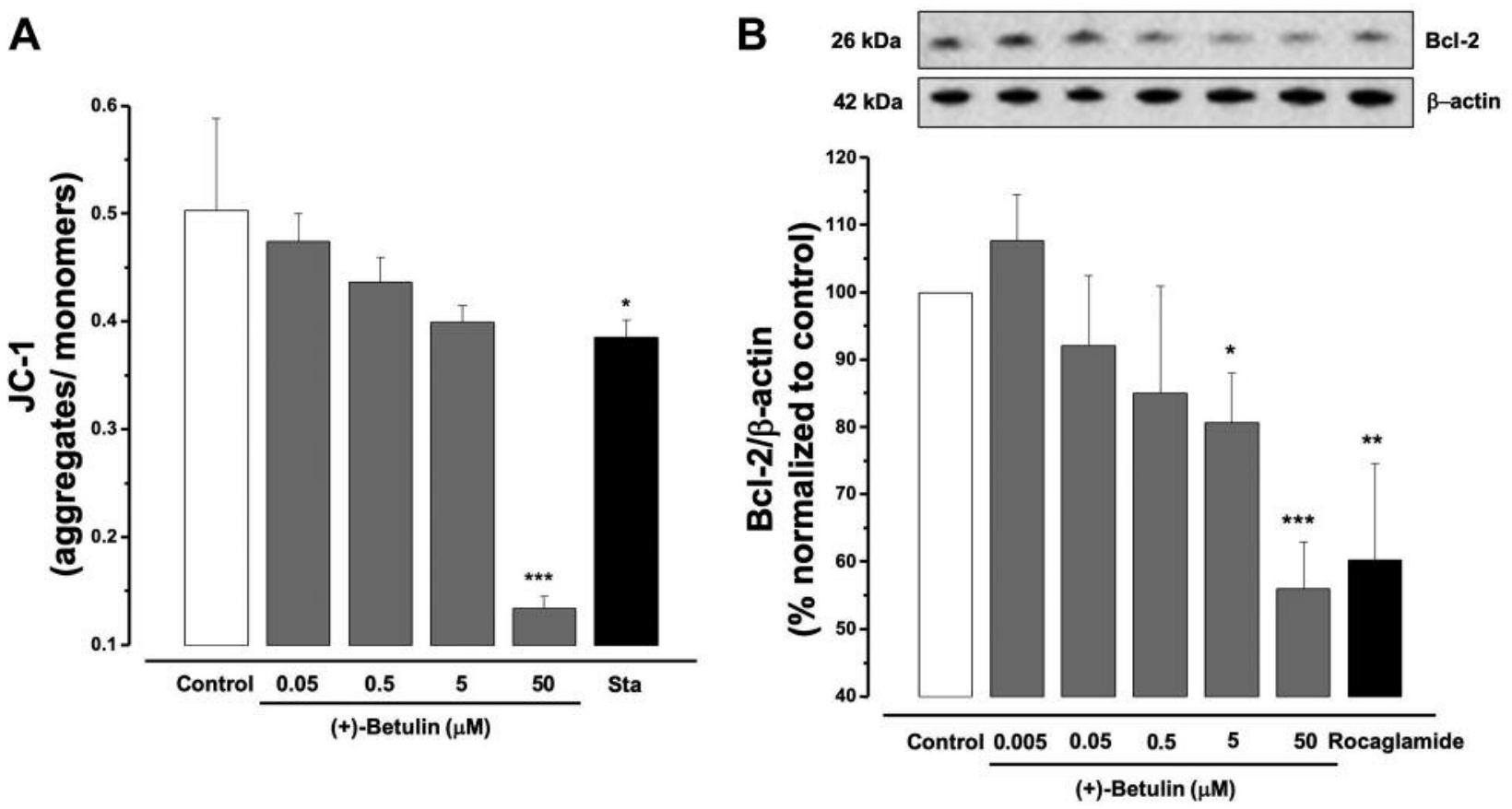

Figure 4. (A) Effect of (+)-betulin on MTP in MDA-MB-231 cells. Cells were treated with (+)-betulin $(0-50 \mu M)$ or staurosporine (Sta, $8 \mu M)$ for $5 \mathrm{~h} .(\mathrm{B})$ Western blot analysis of (+)-betulin on Bcl-2 protein levels. Cells were treated $5 \mathrm{~h}$ with (+)-betulin $(0-50 \mathrm{mM})$ or rocaglamide (positive control $(3 \mu M))$. All data are expressed as the means \pm SEM $(n=3)$ and analyzed by one-way ANOVA using Dunnett's multiple-comparison test compared to control; $* p<0.05, * * p<0.01, * * * p<0.001$.

with much lower concentrations of (+)-betulin, suggesting that apoptotic effect of (+)-betulin may be due to a selective inhibition of the canonical NF-kB pathway. However, further studies are needed to support this hypothesis.

Intercellular adhesion molecule 1 (ICAM-1) is one of the genes directly regulated by NF-kB. This protein is upregulated in inflammatory conditions and is involved in adhesion of cancer cells (28). Additionally, ICAM-1 plays an important role in the metastatic process of cancer cells (29). Metastatic breast cancer patients have low rates of survival, and in some cases the metastatic process is incurable (30). $(+)$-Betulin treatment demonstrated a reduction of the levels of ICAM-1 in MDA-MB-231 cells. Hence, (+)-betulin could be responsible for delaying the metastatic breast cancer process.

Moreover, TNF $\alpha$ is a multifunctional cytokine with several roles such as cell survival, proliferation, differentiation, and death. Effects on this cytokine are triggered by activation of two main signaling pathways: NF$\mathrm{\kappa B}$ and c-Jun $\mathrm{N}$-terminal kinase (JNK). The JNK pathway is related with cell death (31). A recent study showed that $\mathrm{TNF} \alpha$ induces radiotherapy- and chemotherapy-sensitizing effects against breast cancer cells (32). Co-treatment with $(+)$-betulin and TNF $\alpha$ increased the (+)-betulin cytotoxic potential in MDA-MB-231 cells. Since (+)-betulin induced apoptosis by NF-kB pathway inhibition, $\mathrm{TNF} \alpha$ could therefore be involved in the activation of JNK pathway in MDA-MB-231 breast cancer cells.

Mitochondrial apoptosis is triggered by mitochondrial outer membrane permeabilization (MOMP) and finally activation of caspases (33). MOMP is controlled mainly by the BCL-2 family, for which the members can be pro- or anti-apoptotic stimulators (34). The antiapoptotic $\mathrm{Bcl}-2$ protein mainly functions to inhibit the release of cytochrome $\mathrm{c}$ from the mitochondria, an important element for apoptosome formation (34). Hence, compounds with inhibitory activity against antiapoptotic BCL-2 members could be good candidates to treat TNBC. NF-KB has also shown to directly or indirectly regulate the physiology of mitochondria (35) and up-regulate many antiapoptotic proteins, including $X$ chromosome-linked IAP (XIAP), and some BCL-2 family members like Bcl-2, Bcl$\mathrm{XL}$ and A1/Bfl-1 (36). (+)-Betulin induced the loss of MTP and down-regulation of Bcl-2 in MDA-MB-231 cells. These findings agree with those found earlier in Hela cells where (+)betulin induced the release of mitochondrial cytochrome $\mathrm{c}$ and the translocation of both proapoptotic members of the BCL-2 family, Bax and Bak, to the mitochondrial membrane (9). In MDA-MB-231 cells a recent study showed that (+)-betulin increased the expression of some apoptotic targets including BAX, NOXA, PUMA and PERP (11). In HBL-100 cells, (+)- 
A
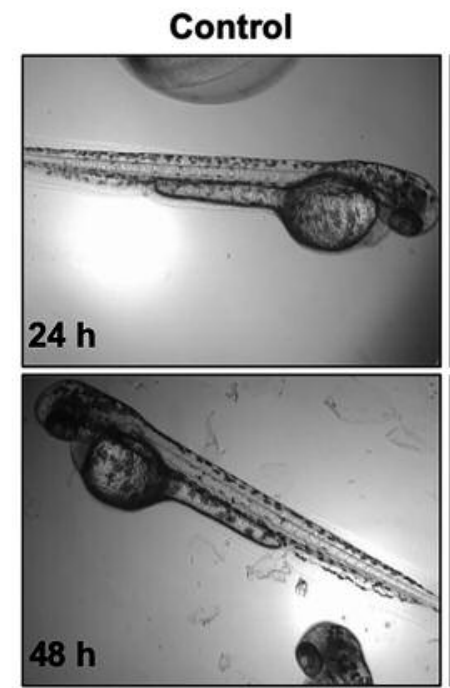

(+)-Betulin
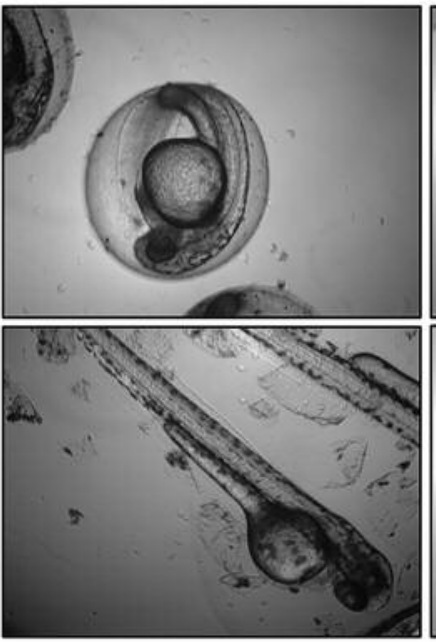

Cycloheximide

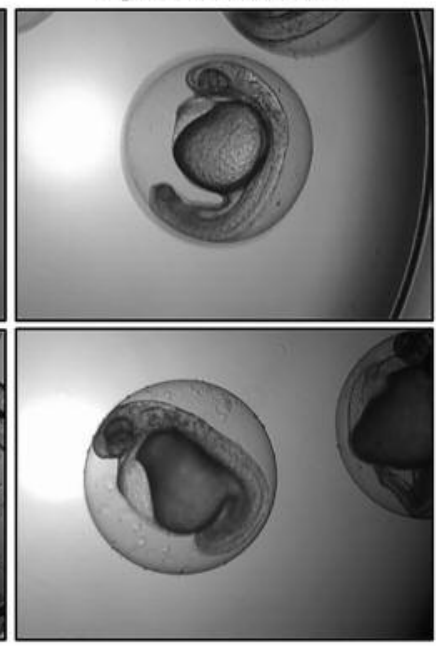

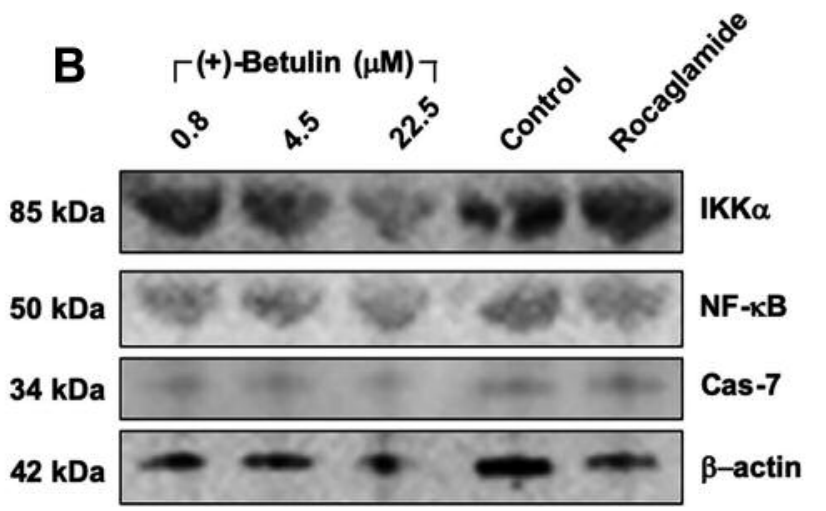

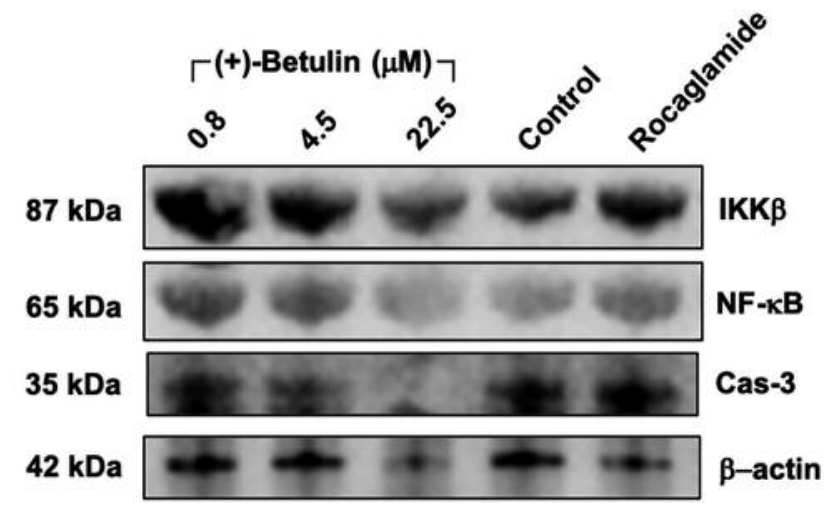

Figure 5. Effects of (+)-betulin on zebrafish. (A) Toxicity on zebrafish development. Embryos at 24 hpf were treated for $24 \mathrm{~h}$ and $48 \mathrm{~h}$ with (+)betulin at $50 \mu \mathrm{M}$ or cycloheximide as the positive control or water as control. (B) Effects of (+)-betulin on the NF-kB pathway in zebrafish. Animals at $72 \mathrm{hpf}$ were treated with betulin at $0,0.8,4.5$ and $22.5 \mu \mathrm{M}$ or rocaglamide $(3 \mu \mathrm{M})$ for $5 \mathrm{~h}$. Western blotting was performed to evaluate IKKa and $\beta, N F-k B$ p50 and p65 expression, and caspase- 3 and -7 expression. $\beta$-actin levels were used as internal controls.

betulin also induced the up-regulation of BAX, cleaved caspase-3 and cleaved PARP levels as well as the downregulation of the Bcl-X protein. Regulation of these genes was linked to up-regulation of the transcription factor TAp63 that belongs to the p53 family (11). It is well-known that NF-kB and p53 trigger opposite functions in cancer. Mutation of p53 in some cancer cells, including MDA-MB-231 cells, has been associated with an increase in NF-kB activity. Also, activation of one of these pathways inhibits the other and vice versa. Hence, inhibition of NF-kB complex by (+)-betulin could be correlated to the $\mathrm{p} 53$ pathway and inhibition of $\mathrm{NF}-\mathrm{kB}$ pathway could be triggered by both intrinsic and extrinsic apoptosis.

Although (+)-betulin did not show toxicity in zebrafish, many proteins of the NF-kB complex were down-regulated. In silico studies also showed interactions of (+)-betulin with
NF-kB isoforms. Similar outcomes were observed in zebrafish embryos treated with BA, which displayed low toxicity in embryogenic development and hatching at a high concentration of $160 \mu \mathrm{M}$ (27). Altogether, these preliminary data support further biochemical and molecular studies to confirm the results in a cancer zebrafish model.

In conclusion, the presented findings revealed that (+)betulin induced apoptosis in MDA-MB-231 breast cancer cells by inhibition of the NF-kB pathway. NF-kB inhibition included changes in cell morphological features and intrinsic and extrinsic apoptosis activation. Also, the fact that (+)betulin shows no developmental toxicity in zebrafish suggests that the polyvalent activity found makes it a possible lead compound for further chemical optimization and for ultimate clinical development for the intervention of TNBC. 


\section{Conflicts of Interest}

The Authors declare no conflicts of interest with regard to the present study.

\section{Authors' Contributions}

G. D. Anaya-Eugenio carried out and analyzed all in vitro and some in vivo experiments and wrote the manuscript; Nicole A. Eggers performed some in vivo studies; Yulin Ren provided the compound (+)-betulin; J. Rivera-Chávez conducted and analyzed the in silico assays; A. Douglas Kinghorn and Esperanza J. Carcache de Blanco coordinated and supervised the study, as well as provided research sources. All Authors read, reviewed, and approved the manuscript.

\section{Acknowledgements}

This work was supported by Program Project grant P01 CA125066 from the National Cancer Institute, National Institutes of Health.

\section{References}

1 Bray F, Ferlay J, Soerjomataram I, Siegel RL, Torre LA and Jemal A: Global cancer statistics 2018: GLOBOCAN estimates of incidence and mortality worldwide for 36 cancers in 185 countries. CA Cancer J Clin 68(6): 394-424, 2018. PMID: 30207593. DOI: $10.3322 /$ caac. 21492

2 Sharma GN, Dave R, Sanadya J, Sharma P and Sharma KK: Various types and management of breast cancer: an overview. $\mathrm{J}$ Adv Pharm Technol Res 1(2): 109-126, 2010. PMID: 22247839.

3 Chun KH, Park JH and Fan S: Predicting and overcoming chemotherapeutic resistance in breast cancer. In: Song E., Hu H. (eds) Translational research in breast cancer. Advances in experimental medicine and biology, vol 1026. Springer, Singapore, pp. 59-104, 2017.

4 Król SK, Kiełbus M, Rivero-Müller A and Stepulak A: Comprehensive review on betulin as a potent anticancer agent. Biomed Res Int 2015: 584189, 2015. PMID: 25866796. DOI: $10.1155 / 2015 / 584189$

5 Boparai A, Niazi J, Bajwa $\mathrm{N}$ and Singh PA: Betulin a pentacyclic tri-terpenoid: an hour to rethink the compound. Open Access J Trans Med Res 1(2): 53-59, 2017. DOI: 10.15406/oajtmr.2017.01.00012

6 So HM, Eom HJ, Lee D, Kim S, Kang KS, Lee IK, Baek K-H, Park JY and Kim KH: Bioactivity evaluations of betulin identified from the bark of Betula platyphylla var. japonica for cancer therapy. Arch Pharm Res 41(8): 815-822, 2018. PMID: 30109574. DOI: $10.1007 / \mathrm{s} 12272-018-1064-9$

7 Hordyjewska A, Ostapiuk A and Horecka A: Betulin and betulinic acid in cancer research. J Pre Clin Res 12(2): 72-75, 2018. DOI: https://doi.org/10.26444/jpccr/92743

8 Zhao J, Li R, Pawlak A, Henklewska M, Sysak A, Wen L, Yi JE and Obmińska-Mrukowicz B: Antitumor activity of betulinic acid and betulin in canine cancer cell lines. In Vivo 32(5): 10811088, 2018. PMID: 30150429. DOI: 10.21873/invivo.11349
9 Li Y, He K, Huang Y, Zheng D, Gao C, Cui L and Jin YH: Betulin indices mitochondrial cytochrome c release associated apoptosis in human cancer cells. Mol Carcinog 49(7): 630-640, 2010. PMID: 20564340. DOI: $10.1002 / \mathrm{mc} .20638$

10 Bębenek E, Kadela-Tomanek M, Chrobak E, Wietrzyk J, Sadowska J and Boryczka S: New acetylenic derivatives of betulin and betulone, synthesis and cytotoxic activity. Med Chem Res 26(1): 1-8, 2017. PMID: 28111514. DOI: 10.1007/s00044-0161713-9

11 Hsu RJ, Hsu YC, Chen SP, Fu CL, Yu JC, Chang FW, Chen YH, Liu JM, Ho JY and Yu CP: The triterpenoids of Hibiscus syriacus induce apoptosis and inhibit cell migration in breast cancer cells. BMC Complement Altern Med (15): 65, 2015. PMID: 25885960. DOI: 10.1186/s12906-015-0592-9

12 Ren Y, Van Schoiack A, Chai HB, Goetz M and Kinghorn AD: Cytotoxic barrigenol-like triterpenoids from an extract of Cyrilla racemiflora housed in a repository. J Nat Prod 78(10): 2440-2446, 2015. PMID: 26422131. DOI: 10.1021/acs.jnatprod.5b00532

13 Ren Y, Anaya-Eugenio GD, Czarnecki AA, Ninh TN, Yuan C, Chai HB, Soejarto DD, Burdette JE, Carcache de Blanco EJ and Kinghorn AD: Cytotoxic and $\mathrm{NF}-\mathrm{kB}$ and mitochondrial transmembrane potential inhibitory pentacyclic triterpenoids from Syzygium corticosum and their semi-synthetic derivatives. Bioorg Med Chem 26(15): 4452-4460, 2018. PMID: 30057155. DOI: $10.1016 /$ j.bmc.2018.07.025

14 Anaya-Eugenio GD, Addo EM, Ezzone N, Henkin M, Ninh TN, Ren Y, Soejarto DD, Kinghorn AD and Carcache de Blanco EJ: Caspase-dependent apoptosis in prostate cancer cells and zebrafish by corchorusoside C from Streptocaulon juventas. J Nat Prod 82(6): 1645-1655, 2019. PMID: 31120251. DOI: $10.1021 /$ acs.jnatprod.9b00140

15 Morris GM, Huey R, Lindstrom W, Sanner MF, Belew RK, Goodsell DS and Olson AJ: AutoDock4 and AutoDockTools4: Automated docking with selective receptor flexibility. J Comput Chem 30(16): 2785-2791, 2009. PMID: 19399780. DOI: $10.1002 /$ jcc. 21256

16 Trott $\mathrm{O}$ and Olson AJ: AutoDock Vina: improving the speed and accuracy of docking with a new scoring function, efficient optimization, and multithreading. J Comput Chem 31(2): 455461, 2010. PMID: 19499576. DOI: 10.1002/jcc.21334

17 Oeckinghaus A and Ghosh S: The NF-kB family of transcription factors and its regulation. Cold Spring Harb Perspect Biol 1(4): a000034, 2009. PMID: 20066092. DOI: 10.1101/cshperspect. a000034

18 Aggarwal BB: Nuclear factor-kB: The enemy within. Cancer Cell 6(3): 203-208, 2004. PMID: 15380510. DOI: 10.1016/ j.ccr.2004.09.003

19 Xia Y, Shen S and Verma IM: NF-kB, an active player in human cancers. Cancer Immunol Res 2(9): 823-830, 2014. PMID: 25187272. DOI: 10.1158/2326-6066.CIR-14-0112

20 Elmore S: Apoptosis: A review of programmed cell death. Toxicol Pathol 35(4): 495-516, 2006. PMID: 17562483. DOI: 10.1080/01926230701320337

21 Saraste A and Pulkki K: Morphologic and biochemical hallmarks of apoptosis. Cardiovasc Res 45(3): 528-537, 2000. PMID: 10728374. DOI: 10.1016/s0008-6363(99)00384-3

22 Galluzi L, Vitale I, Aaronson SA, Abrams JM, Adam D, Agostinis P, Alnemri ES, Altucci L, Amelio I, Andrews DW, AnnicchiaricoPetruzzelli M, Antonov AV, Arama E, Baehrecke EH, Barlev NA, Bazan NG, Bernassola F, Bertrand MJM, Bianchi K, Blagosklonny 
MV, Blomgren K, Borner C, Boya P, Brenner C, Campanella M, Candi E, Carmona-Gutierrez D et al: Molecular mechanisms of cell death: recommendations of the Nomenclature Committee on Cell Death 2018. Cell Death Differ 25(3): 486-454, 2018. PMID: 29362479. DOI: $10.1038 / \mathrm{s} 41418-017-0012-4$

23 Singh R, Letai A and Sarosiek K: Regulation of apoptosis in health and disease: the balancing act of BCL-2 family proteins. Nat Rev Mol Cell Biol 20(3): 175-193, 2019. PMID: 30655609. DOI: $10.1038 / \mathrm{s} 41580-018-0089-8$

24 Hoesel B and Schmid JA: The complexity of NF-kB signaling in inflammation and cancer. Mol Cancer 12: 86, 2013. PMID: 23915189. DOI: $10.1186 / 1476-4598-12-86$

25 Zhang SY, Zhao QF, Fang NN and Yu JG: Betulin inhibits proinflammatory cytokines expression through activation STAT3 signaling pathway in human cardiac cells. Eur Rev Med Pharmacol Sci 19(3): 455-460, 2015. PMID: 25720718.

$26 \mathrm{Wu}$ Q, Li H, Qiu J and Feng H: Betulin protects mice from bacterial pneumonia and acute lung injury. Microb Pathog 75: 2128, 2014. PMID: 25173422. DOI: 10.1016/j.micpath.2014.08.005

27 Jiao L, Wang S, Zheng Y, Wang N, Yang B, Wang D, Yang D, Mei W, Zhao Z and Wang Z: Betulinic acid suppresses breast cancer aerobic glycolysis via caveolin-1/NF-kB/c-Myc pathway. Biochem Pharmacol 161: 149-162, 2019. PMID: 30684465. DOI: $10.1016 /$ j.bcp.2019.01.016

28 Kobayashi H, Boelte KC and Lin PC: Endothelial cell adhesion molecules and cancer progression. Curr Med Chem 14(4): 377-386, 2007. PMID: 17305540. DOI: 10.2174/092986707779941032

29 Benedicto I, Romayor I and Arteta B: Role of liver ICAM-1 in metastasis. Oncol Lett 14(4): 3883-3892, 2018. PMID: 28943897. DOI: $10.3892 / \mathrm{ol} .2017 .6700$

30 Lu J, Steeg PS, Price JE, Krishnamurthy S, Mani SA, Reuben J, Cristofanilli M, Dontu G, Bidaut L, Valero V, Hortobagyi GN and Yu D: Breast cancer metastasis: challenges and opportunities. Cancer Res 69(12): 4951-4953, 2009. PMID: 19470768. DOI: 10.1158/0008-5472.CAN-09-0099
31 Wang $\mathrm{X}$ and Lin Y: Tumor necrosis factor and cancer, buddies or foes? Acta Pharmacol Sin 29(11): 1275-1288, 2008. PMID: 18954521. DOI: 10.1111/j.1745-7254.2008.00889.x

32 Wu X, Wu MY, Jiang M, Zhi Q, Bian X, Xu MD, Gong FR, Hou J, Tao M, Shou LM, Duan W, Chen K, Shen M and Li W: TNF$\alpha$ sensitizes chemotherapy and radiotherapy against breast cancer cells. Cancer Cell Int 17: 13, 2017. PMID: 28127258. DOI: $10.1186 / \mathrm{s} 12935-017-0382-1$

33 Kalkavan $\mathrm{H}$ and Green DR: MOMP, cell suicide as a BCL-2 family business. Cell Death Differ 25(1): 46-55, 2018. PMID: 29053143. DOI: $10.1038 /$ cdd.2017.179

34 Opferman JT and Kothari A: Anti-apoptotic BCL-2 family members in development. Cell Death Differ 25(1): 37-45, 2018. PMID: 29099482. DOI: 10.1038/cdd.2017.170

35 Albensi BC: What is nuclear factor kappa B (NF-kB) doing in and to the mitochondrion? Front Cell Dev Biol 7: 154, 2019. PMID: 31448275. DOI: 10.3389/fcell.2019.00154

36 Paul M, Kemparaju K and Girish KS: Inhibition of constitutive NF-kB activity induces platelet apoptosis via ER stress. Biochem Biophys Res Commun 493(4): 1471-1477, 2017. PMID: 28986259. DOI: 10.1016/j.bbrc.2017.10.011
Received September 2, 2020

Revised October 19, 2020

Accepted October 20, 2020 